\title{
Efficacy of secnidazole-diminazene aceturate combination therapy in the late treatment of Trypanosoma brucei brucei infection in dogs
}

\author{
Ifeanyi Gabriel Eke ${ }^{\oplus 1^{*}}$, Ikenna Onyema Ezeh², Terry Adaeze Ezeudu², Ukamaka Uchenna Eze', \\ Aruh Ottah Anaga ${ }^{1}$, Patrick Azubuike Onyeyili ${ }^{4}$
}

\begin{abstract}
${ }^{1}$ Department of Veterinary Physiology and Pharmacology, Faculty of Veterinary Medicine, University of Nigeria Nsukka, Enugu State Nigeria, ${ }^{2}$ Department of Veterinary Parasitology and Entomology, Faculty of Veterinary Medicine, University of Nigeria Nsukka, Enugu State Nigeria, ${ }^{3}$ Department of Veterinary Medicine, Faculty of Veterinary Medicine, University of Nigeria Nsukka, Enugu State Nigeria, ${ }^{4}$ Department of Veterinary Physiology and Pharmacology, Faculty of Veterinary Medicine, Federal University of Agriculture Makurdi, Benue State Nigeria
\end{abstract}

\begin{abstract}
This study evaluated the efficacy of combination therapy of secnidazole-diminazene aceturate (SEC-DA) in late treatment of dogs experimentally infected with relapsing strain of Trypanosoma brucei brucei. Fifteen dogs were randomly assigned to 5 groups (A-E) of 3 per group. Group A (uninfected untreated), $\mathrm{B}$ (infected untreated), C (infected and treated with DA $(3.5 \mathrm{mg} / \mathrm{kg}$ ) IM stat), D (infected and treated with secnidazole (SEC) $(100 \mathrm{mg} / \mathrm{kg})$ orally for 5 days and DA $(3.5 \mathrm{mg} / \mathrm{kg}) \mathrm{IM}$ stat), E (infected and treated with SEC (200 mg/kg) orally for 5 days and DA $(3.5 \mathrm{mg} / \mathrm{kg})$ IM stat $)$. Dogs were infected intraperitoneally with $5 \times 10^{5}$ trypanosomes and treatment started 14 days post-infection. Data on parasitaemia, hematology and rectal temperature were recorded. Parasitaemia cleared within 3 days in all the SEC-DA treated dogs and there was no relapse parasitaemia. Parasitaemia did not clear in DA monotherapy dogs. All the SEC-DA treated dogs showed significantly $(\mathrm{P}<0.05)$ higher leucocyte counts, red blood cell count, packed cell volume, hemoglobin concentration and lower rectal temperature than DA monotherapy. It was, therefore, concluded that SEC-DA combination is therapeutically more efficacious than DA monotherapy in the late treatment of T.b. brucei infection in dogs.
\end{abstract}

Keywords: Secnidazole. Diminazene aceturate. Combination therapy. Trypanosomosis. Dogs. Relapse.

\section{INTRODUCTION}

Canine trypanosomosis is a protozoan disease characterized by intermittent fever, progressive anemia, cachexia, anorexia, enlarged superficial lymph nodes, edema of the face and corneal opacity. Untreated cases usually end in death (Eloy, Lucheis, 2009). The disease is caused by Trypanosoma brucei brucei, T. congolense and T. evansi in Africa, T. cruzi and T. evansi in South America and T. evansi in Asia (Eloy, Lucheis, 2009). Trypanosoma evansi and T. Cruzi are zoonotic to man (Gomes et al., 2007). Trypanosoma cruzi is the causative organism of the human disease (Chagas disease) in South America (Rosypal et al., 2007). The drug of choice for canine trypanosomosis is diminazene aceturate (DA)

\footnotetext{
*Correspondence: I. G. Eke. Department of Veterinary Physiology and Pharmacology, Faculty of Veterinary Medicine, University of Nigeria Nsukka, Enugu State Nigeria. Phone: +2348037494699. E-mail:ifeanyi.eke@unn.edu.ng
}

(Peregrine, Mamman, 1993). However, treatment failures have led to increase in canine patient mortalities in endemic areas (Onyeyili, Egwu, 1995). Relapse infection or parasitaemia after treatment has been attributed to late treatment, drug resistance, under-dosage or the acquisition of new infections (Onyeyili, Egwu, 1995). Evidence has shown that relapse parasitaemia can occur in dogs that have been treated with adequate doses of DA where re-infection has been precluded (Onyeyili, Anika, 1989; Jibike, Anika, 1991). This relapse of infections is an indication of involvement of the CNS in the progress of the disease.Trypanosomes in the brain evade the effects of DA, as the drug is ionized and the molecules are too large to penetrate the blood brain barrier in therapeutic concentrations (Murray, Jennings, 1982; Onyeyili, Anika 1990). Development of new drugs is expensive and in recent times, no new trypanocide has been introduced into the market. Drug combination has been proposed as a way 
of increasing treatment success in cases of trypanosomosis because of its potential to reduce incidence of adverse drug reaction and relapse infections. However, effective drug combinations with ability to prevent relapse infection and with minimal toxicity have not been successful in dogs. Thus, the need for further research works in the development of effective therapeutic regimen for treatment of canine trypanosomosis. Drug repurposing has been suggested as a solution to the decrease in the rate of introduction of new drugs into the market. Drug repurposing is the process of discovering new uses for a drug patented for a particular disease (Daniel, 2014). Secnidazole is a 5-nitroimidazole used for the treatment of some protozoan diseases like giardiasis, trichomoniasis and amoebiasis. Eke et al., (2017a) reported the antitrypanosomal effects of SEC in rats and therapeutic efficacy of the combination of SEC and DA in murine trypanosomosis (Eke et al., 2017b). Thus, it appears that SEC has the potential to be repurposed for treatment of trypanosomosis in higher animal species like dogs. The objective of the present study, therefore, was to evaluate the therapeutic efficacy of SEC-DA combination therapy in the late treatment of Trypanosoma b. brucei infection in dogs.

\section{MATERIAL AND METHODS}

Fifteen Nigerian indigenous breed of dogs aged $8-10$ months were used for the study. Both male and female dogs were used in the study. They were kept in a fly-proof dog kennel in separate cages and fed with standard commercial pelletized dry dog food. Water was provided ad libitum. Prior to the commencement of the study, the dogs were physically examined, and dewormed with prazisam ${ }^{(\mathrm{R})}$ (fenbendazole, praziquantel and pyrantel pamoate) and screened for the presence of trypanosomes and other hemoprotozoan parasites using Giemsa-stained blood smear and hematocrit buffy coat technique (OIE, 2008). They were vaccinated with distemper, hepatitis, leptospirosis, parainfluenza and parvo-virus polyvalent vaccine (DHLPP) and anti-rabies vaccine (ARV) (Bioveta a.s. Czech Republic).They were acclimatized for 4 weeks.

\section{Ethical standards}

The animal experimental protocol was approved by the Experimental Animal Ethics Committee of the Faculty of Veterinary Medicine, University of Nigeria, Nsukka (approval no: UNFVM/08/15/4) and in compliance with the Federation of European Laboratory Animal Science Association and the European Community Council Directive of November 24, 1986 (86/609/EEC).

\section{Trypanosome stock}

Trypanosoma b. brucei (FedereStrain) used in the study was obtained from the Department of Veterinary Parasitology and Entomology, University of Nigeria, Nsukka. The experimental animals were infected intraperitoneally with $5 \times 10^{5}$ trypanosomes in $1 \mathrm{ml}$ of phosphate buffered saline (PBS). Trypanosomes were quantified using the method of Herbert and Lumsden (1976)

\section{Experimental groups}

The dogs were randomly assigned to 5 groups of 3 dogs per group. They were treated as follows:

Group A: uninfected untreated control

Group B: infected untreated control.

Group C: infected and treated with a single dose of DA $(3.5 \mathrm{mg} / \mathrm{kg}$ ) IM, (standard drug).

Group D: infected and treated with SEC (100 mg/kg) orally once daily for 5 days and a single dose of DA $(3.5 \mathrm{mg} / \mathrm{kg}$ ) IM, subsequently referred to as (SEC-DA $100 / 3.5 \mathrm{mg} / \mathrm{kg}$ ).

Group E: infected and treated with SEC $(200 \mathrm{mg} / \mathrm{kg})$ orally once daily for 5 days and a single dose of DA $(3.5 \mathrm{mg} / \mathrm{kg})$ IM, subsequently referred to as (SEC-DA $200 / 3.5 \mathrm{mg} / \mathrm{kg}$ ).

Treatment was initiated on the $14^{\text {th }}$ day postinfection (d.p.i.), when parasitaemia was well established on assessment of wet blood films (Jennings, Whitelaw, Urquhart, 1977; Onyeyili,Anika, 1989). The choice of doses used in this study was based on the findings of Eke et al., (2017b).

\section{Parameters for assessment of therapeutic efficacy}

\section{Parasitaemia}

The dogs were examined daily for establishment of the trypanosomes. Active infection with the trypanosomes was determined by examination every two days using the blood obtained from the cephalic vein using EDTA as anticoagulant. Wet blood films were used for the detection of the trypanosomes. Parasitaemia was quantified using the rapid matching technique of Herbert and Lumsden (1976). Parasitaemia was monitored daily for the first 6 days post-treatment (d.p.t.) and then every 3 days, up till 40 d.p.t. to determine the time of relapse of infection. Parasite clearance was confirmed by microscopic examination of Giemsa stained thin smears and hematocrit buffy coat (OIE, 2008). Dogs were monitored for 40 d.p.t. 
for reappearance of trypanosomes in the blood (relapse parasitaemia).

\section{Temperature}

Rectal temperatures of the dogs were determined before infection and monitored every other day before treatment with a digital thermometer. After treatment, the rectal temperatures were monitored every day for 6 d.p.t., then every three days for 40 d.p.t.

\section{Hematology}

Blood samples for hematological parameters were collected on days $0,7,14,21$ and 28 , through the cephalic vein into EDTA sample bottles for full blood count using the method of Schalm, Jain and Carroll (1975), while the microhematocrit method was used to determine the PCV (Coles, 1980) every 3 days. Haemoglobin concentration was determined using the cyanomethaemoglobin method (Coles, 1980).

\section{Statistical analyses}

Statistical analysis was conducted using SPSS version 15 for Windows. Repeated measures in general linear model (GLM) was used to analyse the data generated from the study. Variant means were separated using least significant difference (LSD). Significance was accepted at $\mathrm{p}<0.05$. The results were presented as mean \pm SEM in figures and tables.

\section{RESULTS}

\section{Parasitological findings}

Parasitaemia was established in most of the dogs 5 d.p.i. and by 14 d.p.i.; all the infected dogs showed high level of parasitaemia, but there was no significant $(p>0.05)$ difference in their level of parasitaemia. However, there was significant $(p<0.05)$ reduction in parasitaemia in all treated dogs 15 - 19 d.p.i. The percentage reduction in parasitaemia for group C was $97.5-99.8 \%$, group D was $98-100 \%$, while group $\mathrm{E}$ was $98.4-100 \%$ from day $15-19$. However, parasitaemia increased from $49.9-74.9 \%$ within the same period in the untreated. All untreated dogs died before 22 d.p.i. Parasites were completely cleared from the blood of all the SEC-DA treated dogs by 17 d.p.i. and confirmed by examination of the hematocrit buffy coats of the blood of the dogs, while DA monotherapy (group C) maintained a low grade parasitaemia from day 19 until day 30 . On day 31 , there was a surge in parasitaemia in the DA-treated dogs. Relapse of infection did not occur in all the SEC-DA treated dogs throughout the period of this study (40 d.p.t.) (Figure 1).

\section{Rectal temperature}

There was no significant variation in the rectal temperatures of the dogs before infection. But 14 d.p.i., significant $(p<0.05)$ increase in rectal temperature

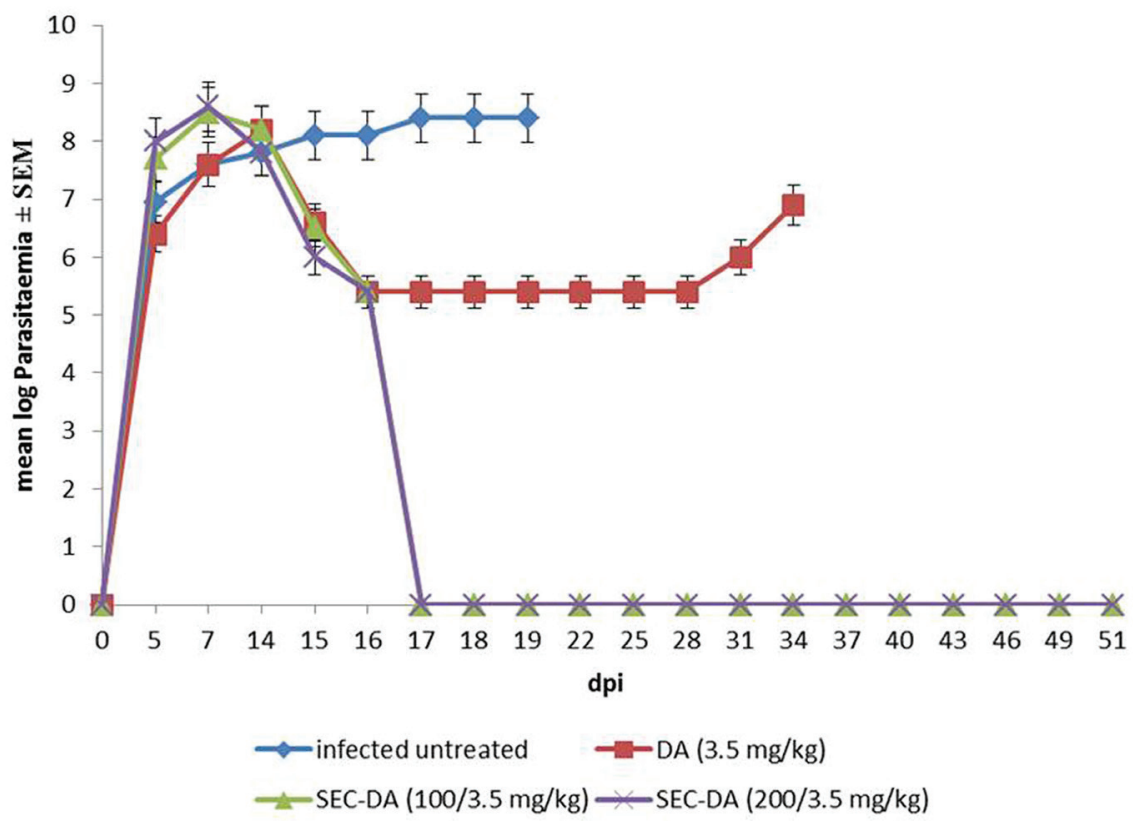

FIGURE 1 - Mean log parasitaemia in dogs infected with T. $b$ brucei and treated with combinations of SEC-DA and DA monotherapy. Dogs were infected on day 0 and treatment started 14 d.p.i. All infected untreated dogs died before 22 d.p.i. Data collection on parasitaemia was terminated for a group as soon as relapse was recorded for that group. 
(2.1-3.6\%) was recorded in all the infected dogs which persisted in the infected untreated dogs when compared with uninfected untreated. One day post-treatment, a significant $(\mathrm{p}<0.05)$ decline in rectal temperature $(1.8 \%)$ was recorded in group $\mathrm{E}$ compared with groups $\mathrm{D}$ and $\mathrm{C}$. Two days posttreatment, there was no significant variation in the rectal temperatures of dogs in groups C, D and E. However, there was a significant rise in the rectal temperatures $(5.4 \%$ and $4.5 \%$ respectively) of dogs in group $\mathrm{C}$ on 22 and 31 d.p.i. compared with groups A, D and E (Figure 2).

\section{Hematology}

\section{Total leucocyte count}

The leucocyte count in the dogs in group E was significantly lower than those of the uninfected untreated control on day 0 . There was no significant $(p>0.05)$ difference in the total leucocyte count between the groups 14 d.p.i. Seven days post-treatment (day 21), there was significantly $(p<0.05)$ higher leucocyte counts in groups $\mathrm{D}$ and $\mathrm{E}$ compared with groups A and B. Fourteen days post-treatment (day 28), total leucocyte was significantly ( $p$ $<0.05$ ) higher in group A compared with groups C, D and E. However, groups D and E had significantly $(\mathrm{p}<0.05)$ higher total leucocyte count than those of group C (Table I).

\section{Lymphocytes}

The mean lymphocyte count of group B dogs was significantly $(\mathrm{p}<0.05)$ higher than those of group $\mathrm{C}$ 14 d.p.i. At 21 d.p.i. (7 d.p.t.), the lymphocyte counts of all dogs in groups $C, D$ and $E$ were significantly $(p<0.05)$ higher than that of group B, while the lymphocyte counts of those in groups D and Ewere significantly $(p<0.05)$ higher than those of group A. Nevertheless, 14 d.p.t. (28 d.p.i.), the lymphocyte counts of the group A dogs were significantly $(\mathrm{p}<0.05)$ higher than those of group $\mathrm{C}$, while there was no significant $(p>0.05)$ variation between groups A, D and E (Table I).

\section{Neutrophils}

Significantly $(\mathrm{p}<0.05)$ higher neutrophil count was recorded in the uninfected untreated dogs 14 d.p.i. compared with groups D and E. Seven days post-treatment, there was no significant variation in the neutrophil count between groups A, C, D and E. Meanwhile significant increase in the neutrophil count was recorded in the group D dogs compared with group B. Fourteen days post-treatment, significantly $(\mathrm{p}<0.05)$ higher neutrophil count was recorded in group A dogs compared with groups C, D and E dogs (Table I).

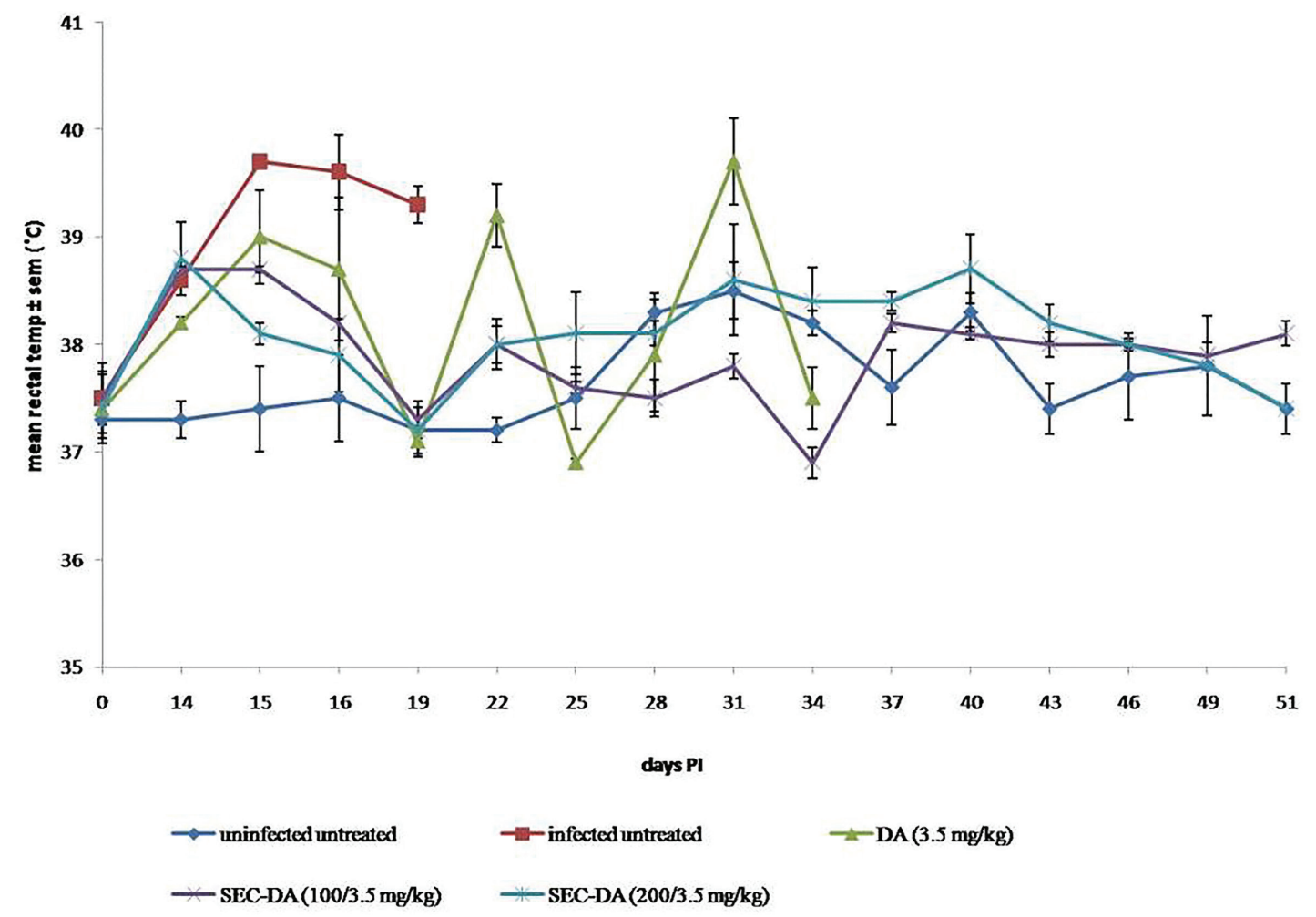

FIGURE 2 - Mean rectal temperatures of dogs infected with T. b. brucei and treated with combinations of SEC-DA and DA monotherapy. Dogs were infected on day 0 and treatment started 14 d.p.i. All infected untreated dogs died before 22 d.p.i. Data collection on rectal temperature for a group was terminated as soon as relapse was recorded for that group. 
TABLE I - Mean total leucocyte, lymphocyte and neutrophil counts in dogs infected with $T$. b. brucei and treated with combinations of SEC-DA and DA alone

\begin{tabular}{|c|c|c|c|c|}
\hline & \multicolumn{4}{|c|}{ Days post-infection } \\
\hline Total leucocyte $(/ \mu \mathrm{L}) \times 10^{3}$ & $\mathbf{0}$ & 14 & 21 & 28 \\
\hline $\mathrm{A}$ & $22.00 \pm 6.54^{\mathrm{a}}$ & $20.07 \pm 0.33$ & $19.43 \pm 4.80^{\mathrm{a}}$ & $17.07 \pm 2.33^{\mathrm{a}}$ \\
\hline B & $21.10 \pm 3.25$ & $15.43 \pm 0.08$ & $17.03 \pm 0.33^{\mathrm{a}}$ & $\mathrm{AD}$ \\
\hline $\mathrm{C}$ & $21.32 \pm 4.41$ & $9.32 \pm 0.83$ & $25.25 \pm 2.23$ & $6.36 \pm 0.97^{\mathrm{bc}}$ \\
\hline $\mathrm{D}$ & $20.72 \pm 3.98$ & $9.32 \pm 2.67$ & $43.08 \pm 10.72^{b}$ & $9.02 \pm 4.49^{\mathrm{bd}}$ \\
\hline $\mathrm{E}$ & $13.48 \pm 1.02^{\mathrm{b}}$ & $14.17 \pm 1.42$ & $41.78 \pm 10.63^{b}$ & $8.55 \pm 1.25^{\mathrm{bd}}$ \\
\hline \multicolumn{5}{|l|}{ Lymphocytes $(/ \mu \mathrm{L}) \times 10^{3}$} \\
\hline $\mathrm{A}$ & $7.20 \pm 0.70$ & $6.60 \pm 4.27$ & $7.80 \pm 0.89^{\mathrm{ac}}$ & $5.50 \pm 1.01^{\mathrm{a}}$ \\
\hline B & $6.50 \pm 1.80$ & $10.10 \pm 4.87^{\mathrm{a}}$ & $4.60 \pm 0.09^{\mathrm{a}}$ & $\mathrm{AD}$ \\
\hline $\mathrm{C}$ & $6.40 \pm 1.42$ & $3.20 \pm 0.82^{b}$ & $18.30 \pm 3.51^{\mathrm{b}}$ & $3.30 \pm 0.62^{\mathrm{b}}$ \\
\hline $\mathrm{D}$ & $6.80 \pm 1.70$ & $5.00 \pm 1.57$ & $23.30 \pm 1.41^{\mathrm{bd}}$ & $4.20 \pm 1.39$ \\
\hline $\mathrm{E}$ & $4.00 \pm 0.64$ & $6.00 \pm 1.14$ & $25.40 \pm 6.48^{\mathrm{bd}}$ & $4.61 \pm 1.11$ \\
\hline \multicolumn{5}{|l|}{ Neutrophils $(/ \mu \mathrm{L}) \times 10^{3}$} \\
\hline $\mathrm{A}$ & $14.11 \pm 3.83$ & $12.91 \pm 4.24^{\mathrm{a}}$ & $11.30 \pm 0.01$ & $10.10 \pm 0.17^{\mathrm{a}}$ \\
\hline B & $13.78 \pm 1.06$ & $9.48 \pm 3.35$ & $4.60 \pm 0.09^{\mathrm{a}}$ & $\mathrm{AD}$ \\
\hline $\mathrm{C}$ & $13.46 \pm 2.41$ & $5.70 \pm 0.33$ & $6.27 \pm 1.52$ & $2.80 \pm 0.53^{\mathrm{b}}$ \\
\hline $\mathrm{D}$ & $12.93 \pm 2.71$ & $4.63 \pm 0.88^{b}$ & $18.04 \pm 7.13^{\mathrm{b}}$ & $4.58 \pm 0.24^{\mathrm{b}}$ \\
\hline E & $8.74 \pm 0.40$ & $4.63 \pm 0.87^{b}$ & $9.04 \pm 2.56$ & $3.83 \pm 0.35^{\mathrm{b}}$ \\
\hline
\end{tabular}

Values on the same row with different superscripts vary significantly $(\mathrm{p}<0.05)$. Dogs were infected on day 0 and treatment started on day 14 post-infection. AD: all dogs in this group died before day 28. A: uninfected untreated, B: infected untreated, C: infected and treated with DA (3.5 mg/kg), D: infected and treated with SEC-DA $(100 / 3.5 \mathrm{mg} / \mathrm{kg})$, E: infected and treated with SEC-DA $(200 / 3.5 \mathrm{mg} / \mathrm{kg})$.

\section{Red Blood Cell (RBC) counts}

There was significant $(\mathrm{p}<0.05)$ reduction $(\leq 50 \%)$ in $\mathrm{RBC}$ counts of all the infected dogs 14 d.p.i. compared with uninfected untreated. However, there was a significant rise (25\%) in the RBC count in the dogs in group E compared with group B, 7 d.p.t. But, the RBC counts in the group A dogs were significantly $(p<0.05)$ higher than all the other experimental groups except those of dogs in group E. Meanwhile, 28d.p.i., the RBC counts of the group A dogs were significantly $(p<0.05)$ higher than those of dogs in group C (Table II).

\section{Hemoglobin $(\mathrm{Hb})$ concentrations}

There was a significant reduction in the $\mathrm{Hb}$ concentration $(\leq 21.5 \%)$ in the entire infected dogs 14 d.p.i. Seven days after treatment (21d.p.i.), there was significantly $(\mathrm{p}<0.05)$ higher $\mathrm{Hb}$ concentration in dogs in groups $\mathrm{D}$ and $\mathrm{E}$ compared with group $\mathrm{C}$ dogs. At 28 d.p.i., the $\mathrm{Hb}$ concentration of group A was only significantly $(\mathrm{p}<0.05)$ higher than those of groups $\mathrm{C}$ and $\mathrm{E}$ (Table II).

\section{Packed Cell Volume (PCV)}

There was no significant difference in the PCV of the dogs in groups C, D and E from $14-16$ d.p.i.; though the PCV values of dogs in groups C, D and E were significantly $(p<0.05)$ higher than those of group $\mathrm{B}$ dogs within this period. Nevertheless, significantly ( $\mathrm{p}$ $<0.05$ ) higher PCV values were recorded in the dogs in groups D and E over those of group C from $19-31$ d.p.i. when group $\mathrm{C}$ dogs relapsed. There was no significant variation between the PCV of dogs in groups $\mathrm{D}$ and $\mathrm{E}$ all through the period of the study except at 19 d.p.i. where the PCV of group E dogs were significantly ( $p$ $<0.05$ ) higher. The PCV values of the group A dogs were significantly $(p<0.05)$ higher than those of the groups $\mathrm{B}$ and $\mathrm{C}$ from 14 d.p.i. to the end of the study. Between the group A dogs and groups D and E dogs, significantly $(p<0.05)$ higher PCV values were recorded at $14-34$ d.p.i. and days $43-49$. By 51d.p.i. (40 d.p.t.), there was no significant variation between the group A dogs and groups $\mathrm{D}$ and $\mathrm{E}$ dogs (Figure 3 ). 
TABLE II - Mean RBC counts and Hemoglobin concentrations in dogs infected with T. b. brucei and treated with combinations of SEC-DA and DA alone

\begin{tabular}{ccccc}
\hline \multicolumn{5}{c}{ Days post-infection } \\
\hline RBC $(\mathbf{\mu L}) \mathbf{~ x 1 0 ~}$ & $\mathbf{0}$ & $\mathbf{1 4}$ & $\mathbf{2 1}$ & $\mathbf{2 8}$ \\
\hline A & $6.19 \pm 1.15$ & $7.62 \pm 0.46^{\mathrm{a}}$ & $7.47 \pm 0.32^{\mathrm{a}}$ & $7.30 \pm 0.15^{\mathrm{a}}$ \\
B & $6.19 \pm 1.06$ & $3.05 \pm 0.01^{\mathrm{b}}$ & $2.13 \pm 0.01^{\mathrm{b}}$ & $\mathrm{AD}$ \\
C & $6.31 \pm 0.56$ & $3.88 \pm 0.05^{\mathrm{b}}$ & $3.69 \pm 0.54^{\mathrm{b}}$ & $3.46 \pm 0.01^{\mathrm{b}}$ \\
D & $7.47 \pm 1.44$ & $4.40 \pm 0.17^{\mathrm{b}}$ & $4.54 \pm 0.29^{\mathrm{b}}$ & $4.71 \pm 0.42$ \\
E & $5.82 \pm 0.21$ & $4.77 \pm 0.52^{\mathrm{b}}$ & $6.44 \pm 1.56^{\mathrm{a}}$ & $5.88 \pm 0.86$ \\
\hline Hemoglobin (Hb) (g/dl) & & & $17.63 \pm 0.26^{\mathrm{a}}$ \\
\hline A & $13.40 \pm 2.48$ & $18.90 \pm 0.45^{\mathrm{a}}$ & $17.77 \pm 0.69^{\mathrm{a}}$ & $\mathrm{AD}$ \\
B & $13.67 \pm 0.37$ & $10.63 \pm 0.32^{\mathrm{b}}$ & $8.20 \pm 0.17^{\mathrm{b}}$ & $12.60 \pm 0.17^{\mathrm{b}}$ \\
C & $16.53 \pm 3.38$ & $12.30 \pm 0.64^{\mathrm{b}}$ & $9.90 \pm 1.50^{\mathrm{b}}$ & $15.07 \pm 1.01$ \\
D & $18.60 \pm 0.42$ & $14.60 \pm 1.16^{\mathrm{b}}$ & $12.27 \pm 0.32^{\mathrm{a}}$ & $13.70 \pm 1.70^{\mathrm{b}}$ \\
E & $15.07 \pm 3.04$ & $13.73 \pm 0.98^{\mathrm{b}}$ & $13.10 \pm 0.40^{\mathrm{a}}$ &
\end{tabular}

Values on the same row with different superscripts vary significantly $(\mathrm{p}<0.05)$. Dogs were infected on day 0 and treatment started on day 14 post-infection. AD: all dogs in this group died before day 28. A: uninfected untreated, B: infected untreated, C: infected and treated with DA $(3.5 \mathrm{mg} / \mathrm{kg})$, D: infected and treated with SEC-DA $(100 / 3.5 \mathrm{mg} / \mathrm{kg})$, E: infected and treated with SEC-DA $(200 / 3.5 \mathrm{mg} / \mathrm{kg}), \mathrm{RBC}$ : red blood cells.

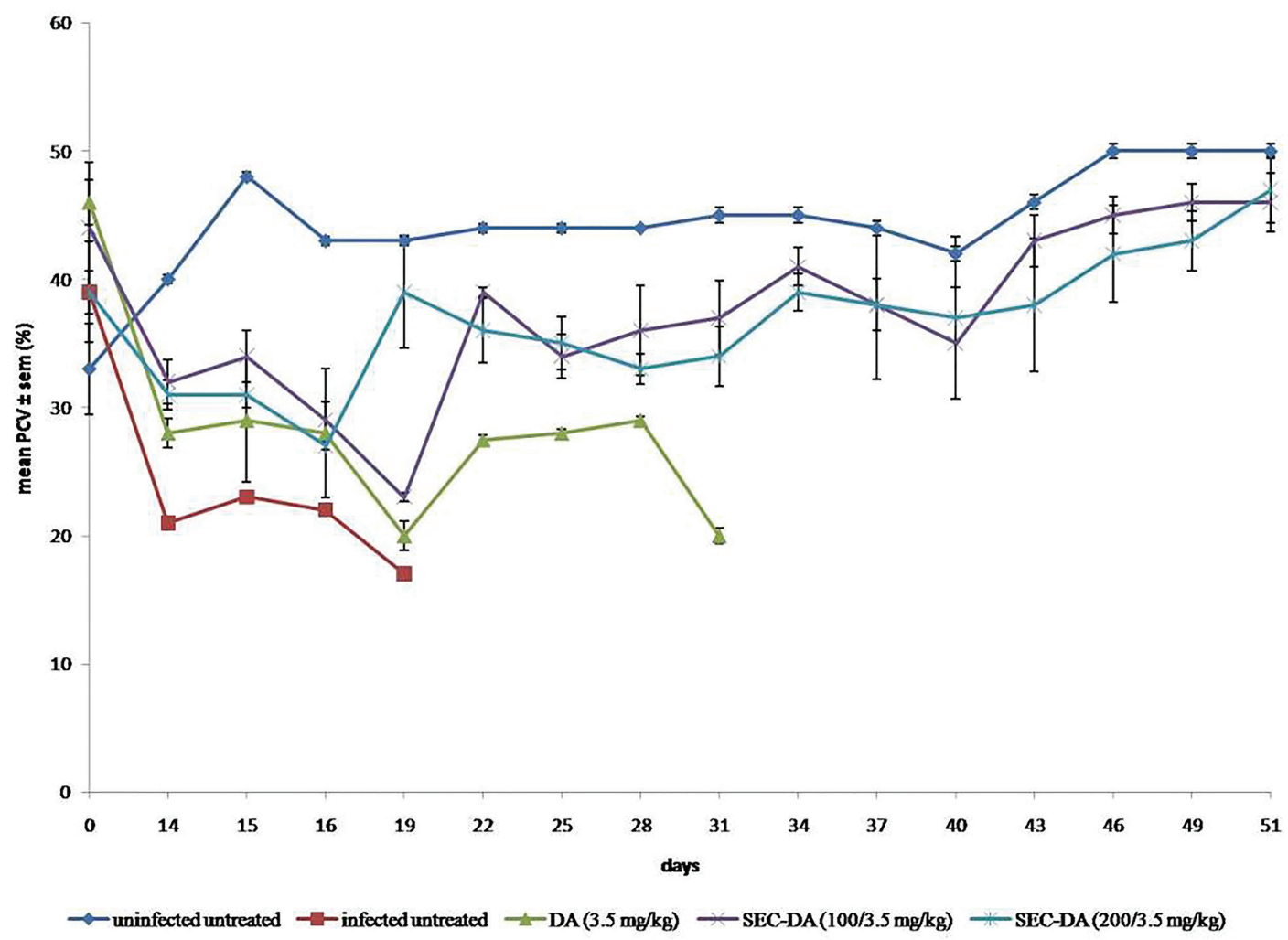

FIGURE 3 - Mean PCV in dogs infected with T. b. brucei and treated with combinations of SEC-DA and DA monotherapy. Dogs were infected on day 0 and treatment started 14 d.p.i. All infected untreated dogs died before 22 d.p.i. Data collection on PCV was terminated for a group as soon as relapse was recorded for that group. 


\section{DISCUSSION}

The SEC-DA combination therapy in dogs was more effective than DA monotherapy at the two different doses tested. There was an earlier and total clearance of parasitaemia in dogs treated with SEC-DA combinations as confirmed by examination of the hematocrit buffy coat and stained thin smears. Also, there was no relapse of infection in all the combined treatment groups up till 40 d.p.t. when the experiment was terminated. However, parasitaemia was not cleared in DA monotherapy group throughout the period of study as parasites were detectable in stained thin smears of blood of the treated dogs. There was also presence of parasites in wet blood films of the dogs treated with monotherapy of DA, 17 d.p.t. (31 d.p.i.). The failure of DA monotherapy to eliminate parasites completely from the blood of treated dogs could be attributed to some of the cardiovascular anomalies associated with trypanosomosis, the molecular size of DA and drug resistance (Losos, Ikede, 1972). The resurgence of parasites in the blood of DA monotherapy dogs reported in this study are in agreement with the findings of Jennings, Whitelaw and Urquhart (1977) and Onyeyili and Anika (1989), who observed that treatment of T. b.brucei infection 14 d.p.i., resulted in relapse of infection. The relapse of infection may have occurred because the DA could not cross the blood-brain barrier in sufficient amounts to bring about cure. Only a very small amount of DA is known to cross the blood-brain barrier, although this small amount may be enough to act synergistically with SEC, through their combined antitrypanosomal effects (Eke et al., 2017b) to eliminate the parasites present within the central nervous system. This may explain the absence of relapse infection in the SEC-DA treated dogs. Undulating fever is one of the cardinal signs of trypanosomosis in dogs and is related to the jig-saw nature of the parasitaemia in animals (Radostits, Blood, Gay, 1994). This was evident in all infected dogs in the present study. Nevertheless, there was more effective and earlier control of fever in SEC-DA treated dogs than in DA monotherapy. Also, fever was observed in DA monotherapy group, 31 d.p.i., which corresponded to the day parasites were detected in wet blood films of treated dogs. The earlier and more effective control of fever in the SEC-DA combined treatments could be related to faster parasite clearance, thereby preventing further release of pyrogens by the parasites (Radosttits, Blood, Gay, 1994). Trypanosomosis is known to alter hematological parameters of infected dogs (Allam et al., 2011). There is usually pancytopenia (Abenga, Ode, Agishi, 2016), associated with immunosuppression and anemia. In the present study, decrease in the leucocyte count was observed 14 d.p.i. in all infected dogs. Although, following treatment with either combinations of SECDA or DA monotherapy, there was increase in the total leucocytes in all the treated dogs. The WBC counts of all dogs in groups $\mathrm{D}$ and Ewere significantly $(\mathrm{p}<0.05)$ higher than those of group C. Very high levels of leucocytes were observed at 21 d.p.i., in groups D and E (SEC-DA $100 / 3.5$ and $200 / 3.5 \mathrm{mg} / \mathrm{kg}$ ), compared to group C (DA $3.5 \mathrm{mg} / \mathrm{kg}$ ). On the other hand, all infected untreated dogs died before 28 d.p.i., while there was resurgence of parasites in the blood of DA monotherapy group 17 d.p.t. (31d.p.i.). Interestingly, there was no relapse of infection in all the SEC-DA combination treatments. The combination therapy of SEC-DA could be responsible for the very high levels of leucocytes observed in groups $\mathrm{D}$ and $\mathrm{E}$ and this may be protective. Thus, it could be inferred that the therapeutic efficacy of combination therapy of SEC-DA was mediated by a combination of immunomodulatory mechanisms and synergistic effects of both drugs. The differential counts showed that the leucocytosis observed 21 d.p.i. in group D (SEC-DA $100 / 3.5 \mathrm{mg} / \mathrm{kg}$ ) was due to elevated lymphocyte and neutrophil counts, while that of group E (SEC-DA $200 / 3.5 \mathrm{mg} / \mathrm{kg}$ ) was due to elevated lymphocytes. Anemia is one of the cardinal signs of trypanosomosis (Anosa, 1983). This is mainly due to RBC destruction, leading to drop in $\mathrm{PCV}$ and $\mathrm{Hb}$ concentration. In the present study, anemia was observed in infected dogs from 14 d.p.i., as there was significant $(p<0.05)$ decrease in $\mathrm{RBC}$ counts, $\mathrm{PCV}$ and $\mathrm{Hb}$ concentrations of infected dogs. Nevertheless, treatment with SEC-DA combinations ameliorated these anomalies; while there was continuous decline in the red cell count of the DA monotherapy dogs. The RBC counts, $\mathrm{PCV}$ and $\mathrm{Hb}$ concentrations of the groups treated with SEC-DA combination were higher than that of DA monotherapy after treatment and up to the end of the experiment. The effects of the combination therapy on the $\mathrm{RBC}$ counts, $\mathrm{PCV}$ values and $\mathrm{Hb}$ concentrations could be related to the faster clearance of parasitaemia and inhibition of relapse of infection.

It was, therefore, concluded that SEC-DA combination therapy was more efficacious and, therefore, a better treatment regimen than DA monotherapy in late treatment of T. b. brucei infection in dogs.

\section{ACKNOWLEDGEMENT}

This work received funding from the Tertiary Education Trust Fund Nigeria Institution Based Research (TETfund IBR). Ref no:TETFund/DESS/UNN/NSUKKA/ RP/Vol. vi 


\section{REFERENCES}

Abenga JN, Ode SA, Agishi G. Haematological derangement patterns in Nigerian dogs infected with Trypanosomabrucei: a simple prototype for assessing tolerance to trypanosome infections in animals.Afr j ClinExperMicrobiol. 2016;17(1):2534.

Allam LD, Ogwu D, Agbede RIS, Sackey AKB. Hematological and serum biochemical changes in gilts experimentally infected with Trypanosomabrucei. Vet Arhiv. 2011;81(5):597-609.

Anosa VO. Mammalian blood cells in health and in trypanosomiasis. Trop Vet. 1983;1(4):177-199.

Coles EH.Veterinary clinical pathology. $3^{\text {rd }}$ ed. Philadelphia, W.B: Sanders Company; 1980.

Daniel S. Repurposing - finding new uses for old and patented drugs: bridging the "valley of death," to translate academic research into new medicines, 18 Marq. Intellectual Property L. Rev. 2014; p. 139. Available at: http://scholarship.law.marquette. edu/iplr/vol18/iss1/5.

Eke IG, Ezeh IO, Ezeudu TA, Eze UU, Anaga AO, Onyeyili PA. Antitrypanosomal activity of secnidazolein vitro and in vivo. Trop J Pharm Res. 2017a;16(3):535-541.

Eke IG, Ezeh IO, EzeuduTA, EzeUU, Anaga AO, Onyeyili PA. Chemotherapeutic efficacy of secnidazole-diminazeneaceturate combination therapy in experimental Trypanosomabruceibrucei infection in rats.Afr J Pharm Pharmacol. 2017b;11(30):349-354.

Eloy LJ, LucheisSB.Caninetrypanosomiasis: etiology of infection and implications for public health.J Venom Anim Toxins incl Trop Dis. 2009;15(4):589-611.

Gomes AH, Ferreira IM, Lima ML, Cunha EA, Garcia AS, Araújo MF. PCR identification of leishmania in diagnosis and control of canine leishmaniasis. Vet Parasitol. 2007;144(34):234-41.

Herbert WJ, Lumsden WH. Trypanosomabrucei: “a rapid matching method" for estimating the host's parasitemia. ExpParasitol. 1976;40(3):427-431.

Jennings FW, Whitelaw DD, Urquhart GM. The relationship between duration of infection with $T$. brucei in mice and the efficacy of chemotherapy.Parasitol. 1977;75(2):143-153.
Jibike GI, Anika SM. Treatment of experimental trypanosomosis in pigs. Brit Vet J. 1991;147(6):556-563.

Losos GJ, Ikede BO. Review of pathology of diseases in domestic and laboratory animals caused by $T$. congolense, $T$. vivax, T. brucei, T. rhodesiense and T. gambiense. Vet Pathol. 1972;9(Suppl):1- 72.

Murray PK, Jennings FW. African trypanosomosis: Chemotherapy in rodent models of sleeping sickness. In: Keush G, Wadstrom T, editors. Animal models for experimental bacterial and parasitic infections. New York: Elsevier; 1983. p. 343-354.

Office International Des Epizootics.OIE.OIE manual of diagnostic tests and vaccines for terrestrial animals. $6^{\text {th }}$ Edition; 2008 .

Onyeyili PA, Anika SM. Effect of combination of DL$\alpha$-difluoromethylornithine and diminazeneaceturate in Trypanosomacongolense infection in dogs. Vet Parasitol. 1990;37(1):9-19.

Onyeyili PA, Anika SM. The influence of Trypanosomacongolense infection on the disposition kinetics of diminazeneaceturate in the dog. Vet Res Comm. 1989;13(3):231-236.

Onyeyili PA, Egwu GO. Chemotherapy of African trypanosomiasis: A historical review. ProtozoolAbstr. 1995;5:229-243.

Peregrine AS, Mamman M. Pharmacology of diminazene: a review. Acta Tropica.1993;54(3-4):185-203.

Radostits OM, Blood DC, Gay CC. Veterinary Medicine: A text book of the diseases of cattle, sheep, pigs, goats and horses. $8^{\text {th }}$ Ed. London, Philadelphia, Toronto, Sydney, Tokyo: WB Saunders; 1994.

Rosypal AC, Cortés-Vecino JA, Gennari SM, Dubey JP, Tidwell RR, Lindsay DS.Serological survey of Leishmaniainfantum and Trypanosomacruzi in dogs from urban areas of Brazil and Colombia. Vet Parasitol. 2007;149(3-4):172-7.

Schalm OW, Jain NC, Caroll EJ. Veterinary haematology. $3^{\text {rd }}$ edition, Philadelphia:Hea and Febiger; 1975.

Received for publication on $31^{\text {st }}$ January 2018 Accepted for publication on $23^{\text {th }}$ September 2018 